\title{
Values and Dangers of Standard Book and Periodical Lists for College Libraries
}

Charles F. Gosnell organized and is librarian of Queens College Library, Flushing, New York.

$\mathrm{S}^{\mathrm{r}}$ TANDARDS serve two purposes: as criteria for past accomplishments, and as bases for present and future action. The present study of standard lists has been a part of an unusual experience of organizing a new college library, depending heavily upon such lists.

Queens College was created late in the spring of 1937 by fiat of the Board of Higher Education of the City of New York. Some buildings were renovated and a staff gathered during the summer; 400 freshmen were admitted to classes in October, 1937. Three and a half years later there is a student body of over 2000 still growing, and a library of 45,000 volumes.

The best way to begin gathering a library in a hurry seemed to be to depend upon standard lists, and multiple copies of the leading lists were among the first books purchased for the new library.

It was immediately apparent that the Shaw List of Books for College Libraries, ${ }^{1}$ begun in 1928 , contained a large propor-

${ }^{1}$ Carnegie Corporation of New York. Advisory Group on College Libraries. A List of Books for College Libraries. Prepared by Charles B. Shaw. A.L.A., I93 1 . 8 rop. tion of out-of-date titles which the college did not need and could not afford. Nevertheless one copy was cut into subject sections and sent out in sections for checking by members of the new departments of instruction. The library staff checked another copy. The checks were combined, and the checked entries clipped and mounted served as excellent order cards.

Mudge's Guide to Reference Books ${ }^{2}$ was similarly checked, but only a small proportion of these titles was found to be necessary or within the grasp of the library. All "basic" titles listed by Shores $^{3}$ were clipped and added to the order file. Careful examination of the Mohrhardt List of Books for Junior College Libraries ${ }^{4}$ showed it to be excellent as a buying list. It was up to date, its titles were of a high quality, quite suited to all years of a four-year liberal arts college. Accordingly all of the 5585 Mohrhardt titles were added to the order list.

To the "standard" titles were added several thousand suggested for immediate purchase by members of the faculty.

\footnotetext{
${ }^{2}$ Mudge, Isadore G. Guide to Reference Books. A.L.A., I936. 504p. Basic Reference Books. Preliminary ed. A.L.A., I937. 406p. (2d ed. 1939 is now available) A.L.A., 1937. 406p. (2d ed. 1939 is ${ }_{4}$ Carnegie Corporation of New York. Advisory Group on Junior College Libraries. $A$ List of Books for Junior College Libraries. Compiled by Foster E. Mohrhardt. A.L.A., I937. $386 \mathrm{p}$.
} 
Nearly three-fourths of the faculty suggestions made independently proved to be duplicated in the standard group. The remaining fourth were incorporated into the buying list. Virtually all of these titles have now been secured.

Thus the Queens College collection is closely related to the standard lists. Some parts were so closely related that checked copies were used as subject guides until catalogers could begin to catch up with the flood of purchases. The lists were tundamental, and suggestive stimulants as well; but in no sense were they regarded as restrictive. They were always subject to reinterpretation in the light of the curriculum.

\section{Periodicals}

As Queens never aims to be a great research library -it has too many rich and generous neighbors in Manhattan-its periodical subscription list is a modest one. In selecting the basic titles, there was heavy leaning upon the subject lists given in each section by Shaw and Mohrhardt, and upon the independent lists compiled by Lyle, ${ }^{5}$ Walter, ${ }^{6}$ and Hilton. ${ }^{7}$ The subscription list for the second year was extensively revised. Many of the more popular items, to be had in public library branches, were eliminated. Other titles, especially foreign ones, and learned journals definitely related to specific courses were added.

Periodicals require, and can be given, more attention per title than books. It is possible for one to be familiar with a periodical year after year as he cannot

5 Lyle, Guy R. Classified List of Periodicals for the College Library. $2 \mathrm{~d}$. ed., rev. and enl. Faxon, 1938. 96p. Frank K Periodicals for the Small

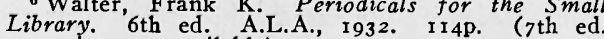
1939, is now available)

7 Hilton, Eugene, and Waples, Douglas. "Periodi cals for the College Library." North Central As sociation Quarterly 8:425*44, Apr. 1934.

JUNE, 1941 be with each book of the month. They can be subject to a continuous re-evaluation in the way that books cannot be. Each new year's selection is based on the past year's experience.

\section{The New Shaw Supplement}

The appearance of the Shaw Supplement $^{8}$ in the spring of 1940 put Queens College Library back into the class of older libraries, enabling a check on past performance against a standard selection which was not available when purchases were made. Queens' holdings of titles in the supplement were checked completely, except for periodicals, and it was found that the library had 52 per cent of the titles. Psychology was the highest class, with 78 per cent. Political science and geology followed with 7 I per cent. The lowest group was religion, with I7 per cent. Queens is a municipal institution, and does not offer courses in this subject. Holdings in the classics were low (small registration in this department) and also in philosophy (courses limited to juniors and seniors, and still being organized).

It was interesting to find a slight general tendency to have a larger proportion of the more recent titles than of the older ones in the $193 \mathrm{I}-38$ list. This tendency was not pronounced in any class (the time span was too short, and the number of titles too small) but it was clearly evident in history and sociology.

Such are the practical values of the standard lists. By inference, the library that makes intelligent use of them ought to be admitted to the inner circles of accredited institutions. It is fairly sure, however, of getting a reasonably good

8 Shaw, Charles B., comp. A List of Books for College Libraries, $1931-38$. A.L.A., I940. $284 \mathrm{p}$. 


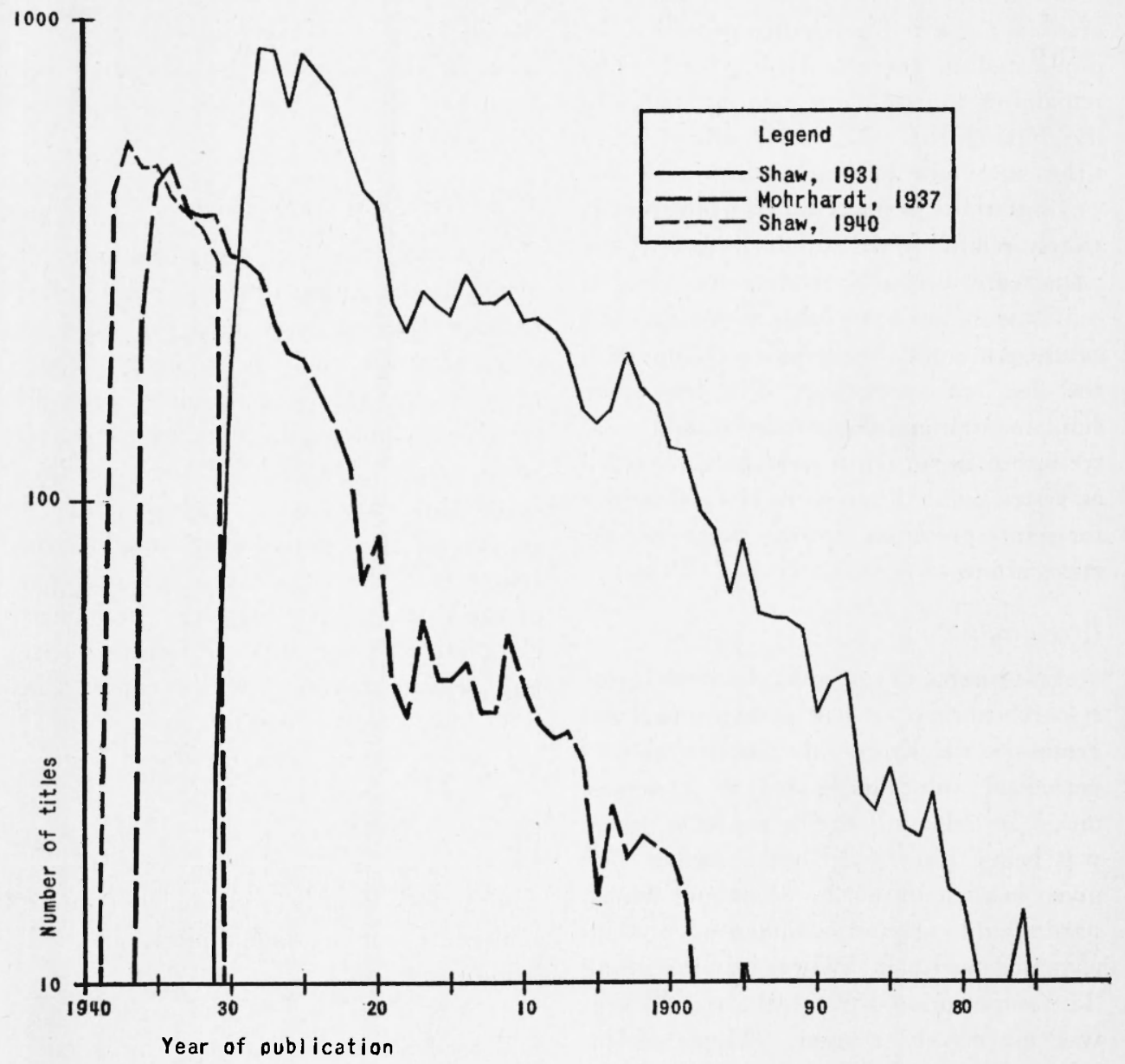

Figure i. Dates of Publication of Titles in Three Standard Lists of Books for College Libraries

collection of books in an economical way.

But I believe that these standards ought to have more lasting values and broader implications than a mere listing of individual titles. We ought to be able to take a list apart and to see what makes a good library book collection. I like to think of the lists as a momentary freezing of the stream that is a good college library book collection. The college library is in a state of continual flux. The lists are permanent only in the sense that they are not constantly remade.

We ought to get some clues to enable us to determine the proper size of a college library collection-assuming that there is an optimum size. Having fixed the size, we should be able to determine the yearly additions required to keep it up to date. Conversely we should have an 
active policy of discarding to avoid stagnation.

\section{Obsolescence and Mortality}

From the interchange of new and old, we should derive a rate of obsolescence and mortality which would be useful for budget and accounting purposes.

If there are mortality tables for humans, why not for books? Like their authors, books grow old and die. The flesh may remain in-mummified form, but the spirit goes. A few books may seem immortal, even in spirit, but they approach immortality through the successive reincarnations of translations and editions.

I refer to the life of a book as reading matter in the college library-as an active everyday participant in the educative process. I exclude 42 line Bibles and First Folios-which are to be looked at and not read, and which are not generally found in college libraries anyway.

Randall $^{9}$ and Eell ${ }^{10}$ have already done some work in the field. With more data, covering a longer period of time, the stimulus of immediate budget problems, and the desire to keep the new collection at Queens alive, I propose to go further. What follows is in the nature of an interim report.

In Figure I are shown on logarithmic scale the distributions by date of publication of titles in three standard lists, Shaw, Mohrhardt, and the Shaw supplement. It is immediately apparent that the relatively recent books predominate in each list. No adjustment has been made for fluctuations in actual book production, but such fluctuations are certainly not

${ }^{\circ}$ Randall, William M. "The College Library Book Budget." Library Quarterly I:42I-35, Oct. I93I. ${ }^{10}$ Eells, Walter C. "Recency as a Measure of Book Collections." Junior College Journal 8:308-Io, Mar. 1938 . sufficient to account for the predominance of recent titles, particularly in the last two decades. The drop in production between 1915 and 1920 , due to war conditions, is reflected in the curves, but otherwise their slope is nearly a straight line. Adjustments for such fluctuations will smooth the curves to a great extent.

It may be inferred that consciously or unconsciously the compilers of these lists preferred the more recent books. If a compiler were to do his work over again, in later years, but with the same standards of selection, the curve would remain approximately the same, except for displacement in time. The peak would advance a number of years corresponding to the time elapsed.

\section{Book Obsolescence}

Figure 2 illustrates such a conjecture in simplified form. A hypothetical list of books issued in 1920 had its peak between 1910 and 1920, and contained almost no books published prior to 1870 . A similar list, of the same size, and compiled on the same basis twenty years later, in I940, shows a peak between 1930 and 1940. It has almost no books older than fifty years, or published before 1890 . Area A represents the new books in the

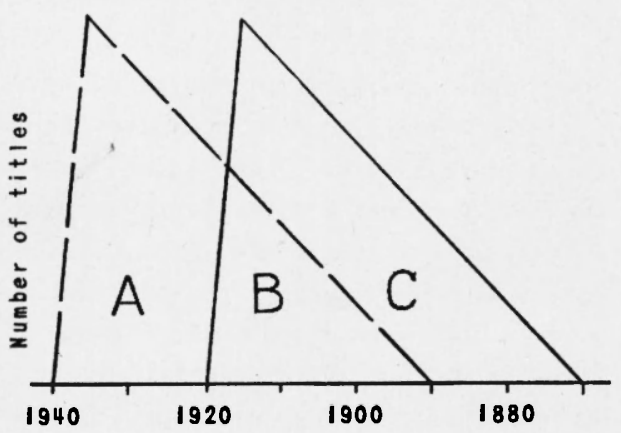

Figure 2. Book Obsolescence 
I940 list not included in the 1920 list. Area B includes books common to both lists. Area $\mathrm{C}$ represents books in the old list but dropped from the new. Area C is equal to Area A. Area A represents the births and $C$ the deaths in the passage of twenty years.

Similar curves, plotted for individual subject classes, show wide differences in their slopes or rates of decline. The peak for classics is not high, and the drop is very slow. Chemistry has a high peak, and drops sharply. Other subjects tend to vary with the speed of research and development in the field.

This family of curves resembles the generally recognized "decay" curves, including the curve of organic decay, certain obsolescence, depreciation and mortality curves, and even the classic curve of forgetting developed by Ebbinghaus.

Three mathematical formulae may be considered: Pearson's type I and III curves, and the exponential curve:

$$
y=b e^{-a x}
$$

This last is easiest to use. But it does not take care of the lag in selection during the time the list is being compiled. Here

$$
\begin{aligned}
& \mathbf{y}=\text { number of titles } \\
& \mathrm{x}=\text { years elapsed }
\end{aligned}
$$

Two parameters may be regarded as keys to the character of the collection or selection:

$b=$ maximum number of books for any one year (i.e., when $\mathrm{x}=\mathrm{o}$ )

$\mathrm{a}=$ the index to rate of obsolescence in the group

If this formula and these parameters can be established for general collections and subject subdivisions, a library can be tested at any time by taking a sampling $\checkmark$ of its titles. A glance at the resulting curve will show whether the library is steadily adding new material, and whether there is progressive discarding of old. It will be possible to substitute objective ratings in place of the intangible terms "live" and "up-to-date."

Presentation of objective data on obsolescence in terms which budget makers and accountants can understand should be of great help when the librarian seeks funds for the new books each year. 